\title{
Commentary \\ Propylthiouracil (PTU) Hepatoxicity in Children and Recommendations for Discontinuation of Use
}

\author{
Scott A. Rivkees ${ }^{1}$ and Donald R. Mattison ${ }^{2}$ \\ ${ }^{1}$ Yale Pediatric Thyroid Center, Yale University School of Medicine, New Haven, CT 06520, USA \\ ${ }^{2}$ Obstetric and Pediatric Pharmacology Branch, Eunice Kennedy Shriver National Institute of Child Health and Human Development, \\ National Institutes of Health, Bethesda, MD 20892, USA \\ Correspondence should be addressed to Scott A. Rivkees, scott.rivkees@yale.edu
}

Received 5 April 2009; Accepted 7 April 2009

Propylthiouracil (PTU) was introduced for clinical use in July 1947 for Graves' disease (GD) treatment. Over the 60 years that this medication has been used, reports of PTU-related liver failure and death have accumulated. On October 28, 2008, an expert panel evaluated PTU drug safety in children at the Eunice Kennedy Shriver National Institute of Child Health and Human Development (NICHD) It is estimated that about 4000 pediatric patients per year with GD are being treated with antithyroid drugs (ATDs) in the United States, and up to $30 \%$ of pediatric patients with GD are being treated with PTU. The risk of severe PTU-induced liver failure is estimated as 1 in 2000-4000 children. The number of children developing reversible PTU-induced liver injury is estimated to be at least 1 in 200. Routine biochemical surveillance of liver function and hepatocellular integrity is not useful in identifying children who will develop liver failure. Children appear to be at higher risk for PTU-induced liver injury than adults. PTU should not be used as first line therapy for the treatment of GD in children. Current PTU use in children taking this medication should be stopped in favor of alternate therapies.

Copyright (C) 2009 S. A. Rivkees and D. R. Mattison. This is an open access article distributed under the Creative Commons Attribution License, which permits unrestricted use, distribution, and reproduction in any medium, provided the original work is properly cited.

\section{Propylthiouracil}

Graves' disease (GD) is the most common cause of hyperthyroidism and is treated with antithyroid drugs (ATDs), radioactive iodine, or surgery [1]. In the pediatric population, the ATDs propylthiouracil (PTU) and methimazole (MMI) are widely used as first line therapy, with many children treated with ATDs for extended periods [1].

Propylthiouracil (6-propyl-2-thiouracil), was introduced for clinical use in July 1947 and has played a seminal role in the treatment of hyperthyroidism [2, 3]. PTU acts by inhibiting the enzyme thyroperoxidase, which adds iodide to tyrosine residues on the thyroxine hormone precursor thyroglobuoine [4]. PTU also inhibits the enzyme tertaiodothyronine $5^{\prime}$ deiodinase, which converts thyroxine (T4) to triiodothyronine (T3) [5].

Whereas countless individuals have benefited from PTU therapy, over the 60 years that this medication has been used, reports of PTU-related liver failure and death in children and adults have accumulated $[6,7]$. These observations raise major concerns about the safety of this medication, especially in children.

\section{Case Reports}

Twenty nine cases of PTU-induced liver failure have been reported in individuals with ages ranging between 6 and 62 years [8-42]. Recovery from liver failure without transplant occurred in 18 individuals, transplantation occurred in 3 persons, and 9 deaths were reported. Of these cases, 14 were pediatric patients $[8,12,14,21,22,25,26,29,31$, $35,37,39,41,43$ ] (Table 1). There were three deaths in PTU-treated pediatric patients. Five children who underwent liver transplantation have been reported.

In comparison with reports of PTU-induced hepatocellular necrosis, liver-related problems associated with MMI use are related to cholestasis, which has been reported in 20 adults [44-53]. MMI-related cholestasis is associated with high doses and older age [51]. There is one case report of MMI-related liver failure leading to death in a 43-year-old man with hyperthyroidism and hepatitis B [54]. The death of a 20 -year-old woman treated with $90 \mathrm{mg} /$ day of methimazole for eight months has been reported [26].

We are unaware of reports of MMI-related liver failure, liver transplants, or deaths in pediatric patients. 


\section{Adverse Event Reports}

Data from 48 US Food and Drug Administration (FDA) reports and ATD-related adverse event (AE) reports in individuals $<18$ years of age from 1970 to 1997 were available as part of a previous analysis of pediatric GD treatment [55]. Thirty-four reports were related to PTU; 14 reports were related to MMI (Table 2).

PTU-related AEs included rashes, leukopenia, arthritis, vasculitis, liver injury, and death. PTU was associated with hospitalization in 18 children. Liver injury was reported in 18 patients. The time from onset of therapy until recognized liver injury was 1 to 23 months. Renal failure due to vasculitis was reported in three children taking PTU.

MMI-related AEs included rashes, urticaria, arthralgias, and vasculitis. There were no reports of liver or renal injury. MMI-related AEs were associated with hospitalization in three children. There were no reports of MMI-induced liver failure, liver transplants, or deaths.

\section{Cohort Studies}

Studies reporting outcomes of pediatric GD treated with PTU, in which AEs were discussed, were evaluated [5662] (Table 3). These cohorts included more than 550 PTUtreated patients. AEs related to PTU use occurred in 15 to $35 \%$ of children, except for one report that described AEs in 1 of 63 patients.

Cohort studies describing AEs related to MMI are few. In a recent study of the MMI analog carbimazole, of 147 treated children, eight children developed rashes, and one child developed agranulocytosis [58].

\section{Liver Transplantation Data}

In 2004, drug-induced liver injury was reported to account for $15 \%$ of liver transplants in the Organ Procurement and Transplantation Network (OPTN) and United Network for Organ Sharing (UNOS) database [64]. Acetaminophen accounted for $50 \%$ of drug-related transplants, followed by isoniazid (17\%) [64]. PTU was the third most common cause of drug-induced liver failure, accounting for $10 \%$ of drug-related transplants [64]. The age range of PTU-related transplant recipients was 6 to 69 years [64].

As of September 22, 2008, data from OPTN and UNOS reveal a total of 23 PTU-related liver transplants from 1990 to 2007 . 30\% of liver transplant recipients were pediatric patients (Table 4). No MMI-related liver transplants occurred over this period in either children or adults.

\section{NICHD, OPPB Workshop}

The above concerns about a PTU safety were relayed to the NICHD Obstetric and Pediatric Pharmacology Branch (OPPB) [7]. Under the umbrella of the Best Pharmaceuticals for Children Act (information on BPCA is available at: http://bpca.nichd.nih.gov/), a workshop was held at the Eunice Kennedy Shriver National Institute of Child Health and Human Development (NICHD) on October 28, 2008 to evaluate PTU drug safety in children.

Workshop participants included members of the NIH and FDA and experts in thyroidology, pediatric endocrinology, hepatology, epidemiology, and adverse event surveillance. Speakers included Vicky Border-Hemphill, Pharm D (FDA), James Boyer, M.D. (Yale University), Wida Cerikh, Ph.D. (United Network for Organ Sharing), David S. Cooper, M.D. (Johns Hopkins University School of Medicine), James Korelitz, Ph.D. (Westat Research), Scott A. Rivkees, M.D. (Yale University), John Senior, M.D. (FDA), Robert Squires Jr., M.D., (University of Pittsburgh), Joslyn Swann, Pharm D., (FDA), and Ana Szarfman, M.D. (FDA). Surendra Varma, M.D. represented the American Academy of Pediatrics (AAP).

The following ATD-related information was evaluated: published reports of AEs, FDA averse event reports (AERs), prescribing practices, Pediatric Acute Liver Failure network data, and OPTN UNOS liver transplantation data. Minutes of this meeting are currently available [7]. The following observations and estimates were made.

(1) The prevalence of GD in children in the United States is about 1 in 10000 children. About 4000 pediatric patients per year with GD are being treated with ATDs in the United States. In 2004, 40\% of children with GD were treated with PTU. Over the past four years, the number of PTU prescriptions for children with GD has decreased by about $50 \%$, and the number or prescriptions for MMI have increased by about $50 \%$.

(2) The risk of PTU-induced liver failure leading to transplantation is about 1 in $2000-4000$ children. (About 0.5 PTU-related liver transplants per year in children; 1000 to 2000 children per year taking PTU.) Once PTU-induced liver failure occurs, it is rapidly progressive with a low chance of reversibility. The number of children developing PTU-induced liver injury that is reversible is estimated to be at least tenfold greater than the number of children who develop liver failure requiring transplantation.

(3) Routine biochemical surveillance of liver function and hepatocellular integrity (serum bilirubin, alkaline phosphatase and transaminase levels) will not be useful in identifying children who will develop PTUinduced liver failure.

(4) Children are at higher risk for PTU-induced liver injury than adults.

(5) PTU-induced liver injury is an important concern for the adult population. The number of adults with GD is at least fourfold higher than the number of children with GD. The proportion of adult patients prescribed PTU for GD is currently greater than the proportion of pediatric patients prescribed PTU. Whereas the proportion of children prescribed PTU for GD has decreased over the past four years, PTU prescribing practices have remained steady in the adult population. 
TABLE 1: Case reports of propylthiouracil-related liver injury in pediatric patients.

\begin{tabular}{|c|c|c|c|c|c|c|}
\hline Authors, year & Age (years) & Gender & Daily dose (mg) & Duration of PTU & Liver abnormality & Outcome \\
\hline Moore, 1946 [8] & 12 & $\mathrm{~F}$ & 300 & 0.5 months & Liver injury & Recovery \\
\hline Parker, 1975 [12] & 9 & $\mathrm{~F}$ & 300 & 2 months & Portal inflammation cholestasis & Recovery \\
\hline Reddy, 1979 [14] & 10 & $\mathrm{~F}$ & 300 & 1.2 months & Hepatitis & Recovery \\
\hline Bloch et al., 1985 [21] & 12 & M & 450 & 2 months & Hepatitis & Recovery \\
\hline Garty et al., 1985 [22] & 12 & $\mathrm{~F}$ & 300 & 1 month & Hepatitis & Recovery \\
\hline $\begin{array}{l}\text { Limaye and Ruffolo, } 1987 \\
\text { [24] }\end{array}$ & 6 & $\mathrm{~F}$ & 300 & 4 months & Hepatitis & Recovery \\
\hline $\begin{array}{l}\text { Jonas and Eidson, } 1988 \\
\text { [25] }\end{array}$ & 13 & $\mathrm{~F}$ & 300 & 7 months & Massive necrosis & Death \\
\hline Baker et al., 1989 [26] & 9 & $\mathrm{~F}$ & 300 & 3 months & Hepatitis & Recovery \\
\hline Kirkland, 1990 [29] & 9 & $\mathrm{~F}$ & 300 & 4 months & Liver failure & Transplant/Recovery \\
\hline Levy, $1993[31]$ & 11 & $\mathrm{~F}$ & 300 & 14 months & Liver failure & Death \\
\hline $\begin{array}{l}\text { Deidiker and deMello, } 1996 \\
\text { [41] }\end{array}$ & 13 & $\mathrm{~F}$ & 250 & 4 months & Liver failure & Transplant/Death \\
\hline Williams et al., 1997 [43] & 14 & $\mathrm{~F}$ & 450 & 4 months & Liver failure & Transplant/Recovery \\
\hline Testa et al., 2003 [35] & 17 & $\mathrm{~F}$ & 450 & 6 months & Liver failure & Transplant/Recovery \\
\hline Sipe et al., 2006 [37] & 7 & $\mathrm{~F}$ & 300 & 9 months & Liver failure & Transplant/Recovery \\
\hline
\end{tabular}

TABLE 2: Adverse events reported to the FDA from 1970 to 1997 in individuals $\leq 18$ years of age.

\begin{tabular}{lcc}
\hline Adverse event & Propylthiouracil & Methimazole \\
\hline Total number & 34 & 14 \\
Hospitalizations & 18 & 3 \\
Deaths & 2 & 0 \\
Liver injury: mild & 1 & 0 \\
Liver injury: serious & 13 & 0 \\
Liver transplantation & 2 & 0 \\
Liver injury-related death & 2 & 0 \\
Agranulocytosis & 1 & 1 \\
Leukopenia & 3 & 1 \\
Thrombocytopenia & 1 & 0 \\
Renal injury & 3 & 0 \\
Vasculitis & 3 & 1 \\
Arthritis & 1 & 2 \\
Arthralgia & 1 & 1 \\
Rash/urticaria & 5 & 9 \\
\hline
\end{tabular}

(6) MMI is not associated with a risk liver failure in the pediatric population.

(7) PTU is associated with much higher risk of antineutrophil cytoplasmic antibody (ANCA) development and vasculitis than MMI.

(8) PTU and MMI have comparable rates of agranulocytosis $(0.3 \%$ in adults). The risk of agranulocytosis is dose-dependent with MMI but not with PTU. The risk of agranulocytosis is very low with low doses of MMI.
(9) MMI use during pregnancy is associated with an increased risk of birth defects (aplasia cutis, choanal atresia, esophageal atresia, tracheoesophagel fistulas, and athelia). PTU use during pregnancy is not associated with birth defects. Women should be informed of the potential risks of PTU-hepatotoxity and risks of MMI-associated fetal minor malformations when considering ATD use during pregnancy.

(10) Even though there was more MMI than PTU use in children over periods when PTU-induced liver failure has been reported, there are no reports of liver failure or liver transplants associated with MMI use in children. There are also fewer and less serious AERs in the FDA database for MMI than PTU.

(11) There is no good plan for managing hepatotoxicity risk in a PTU-treated patient, other than not using the drug.

\section{The Need to Consider Alternatives to PTU}

Considering the above, we believe that PTU should never be used as first line treatment in children with GD $[6,65]$. We also believe that it is reasonable and prudent to discontinue PTU use in the children taking this medication for the treatment of GD.

In the United States and many countries, MMI is available and should be considered as the alternative ATD to PTU. In several countries, carbimazole [66], which is converted to MMI, is available and should be considered as the alternative ATD to PTU.

When using MMI in the treatment of GD, practitioners should consider the following. In comparison with PTU, MMI dosing is more convenient and associated with better compliance [67], as the tablets are small (5 or $10 \mathrm{mg}$ ), and 
TABle 3: Pediatric cohort studies of propylthiouracil-related adverse events.

\begin{tabular}{|c|c|c|c|c|}
\hline Authors, year & $N$ & $\mathrm{AE}(n)$ & $\% \mathrm{AE}$ & Adverse events \\
\hline \multirow{11}{*}{ Hamburger, 1985 [57] } & \multirow{11}{*}{182} & \multirow{11}{*}{31} & \multirow{11}{*}{$17 \%$} & 11 Cutaneous \\
\hline & & & & 1 Cutaneous and neutropenia \\
\hline & & & & 1 Cutaneous and rheumatological \\
\hline & & & & 1 Cutaneous and hepatic \\
\hline & & & & 1 Cutaneous and pharyngitis \\
\hline & & & & 4 Neutropenia \\
\hline & & & & 2 Hepatic \\
\hline & & & & 1 Rheumatological \\
\hline & & & & 2 Nausea \\
\hline & & & & 5 Multiple infections without neutropenia \\
\hline & & & & 1 Unspecified \\
\hline Lippe et al., 1987 [59] & 63 & 1 & $1.5 \%$ & 1 Arthritic reaction \\
\hline Ward et al., 1999 [62] & 33 & 8 & $24 \%$ & Rash, arthralgia, nausea, vomiting \\
\hline \multirow{2}{*}{ Lazar et al., 2000 [63] } & \multirow{2}{*}{28} & \multirow{2}{*}{14} & \multirow{2}{*}{$35 \%$} & 2 Major; agranulocytosis; toxic hepatitis \\
\hline & & & & 12 Minor \\
\hline \multirow{2}{*}{ Somnuke et al., 2007 [61] } & \multirow{2}{*}{32} & \multirow{2}{*}{2} & \multirow{2}{*}{$6 \%$} & ANCA; nephritis \\
\hline & & & & Rash, arthralgia \\
\hline \multirow{7}{*}{ Glaser and Styne, 2008 [56] } & \multirow{7}{*}{70} & \multirow{7}{*}{11} & \multirow{7}{*}{$16 \%$} & 1 Rash \\
\hline & & & & 2 Rash and arthralgia \\
\hline & & & & 1 Arthritis with purpura \\
\hline & & & & 1 Arthritis with purpura, hematuria \\
\hline & & & & 3 Elevated liver function tests \\
\hline & & & & 2 Marked elevated liver function tests \\
\hline & & & & 2 Neutropenia \\
\hline \multirow{2}{*}{ Ma et al., 2008 [60] } & 40 & 8 & $20 \%$ & 6 Serious \\
\hline & 48 & 7 & $14.6 \%$ & NA \\
\hline
\end{tabular}

MMI can be given once daily [4]. The MMI dose range is typically used by our center is 0.1 to $0.3 \mathrm{mg} / \mathrm{kg}$ per day, with doses given once daily. Because MMI comes in 5 and $10 \mathrm{mg}$ tablets, which are small and difficult to cut precisely, we commonly prescribe the following doses: infants, $1.25 \mathrm{mg}$ per day; 1 to 5 years, 2.5 to $5.0 \mathrm{mg}$ per day; 5 to 10 years, 5 to $10 \mathrm{mg}$ per day; 10 to 18 years, 10 to $20 \mathrm{mg}$ a day. With severe hyperthyroidism (free $\mathrm{T} 4>4 \mathrm{ng} / \mathrm{dL}$ ), doses $50 \%$ to $100 \%$ higher than above can be used.

Although MMI has a better overall safety profile than PTU, MMI is associated with minor adverse events that may affect up to $10 \%$ of children. MMI-related adverse events include allergic reactions, rashes, myalgias, and arthralgias. Agranulocytosis has been reported in about $0.3 \%$ of adult patients taking MMI or PTU [4, 68, 69]. Agranulocytosis is dose-dependent with MMI and rarely occurs at low doses [4, 68, 69]. When it develops, agranulocytosis develops over the first 100 days of therapy in $95 \%$ of individuals $[4,68,69]$. Thus, if a patient taking MMI feels ill for any reason, they should immediately discontinue their medication and contact their physician. Although side effects to MMI most commonly occur within the first 6 months of therapy, adverse events can occur with prolonged therapy. In our clinical practice, we find that $4 \%$ of children on MMI developed adverse events after 18 months of therapy.

The issue of how long ATDs should be used in children before considering either radioactive iodine or surgery warrants further study. Many practitioners will consider a trial of ATDs for up to two years and proceed to surgery or radioactive iodine if remission (i.e., euthyroid after cessation of ATDs) does not occur. Practitioners may also elect to continue antithyroid medications for longer as long as toxic reactions do not occur.

Properly administered, radioactive iodine is an acceptable and effective treatment for GD in the pediatric population [70]. The use of radioactive iodine in the pediatric population, though, is viewed as controversial by some [71].

The goal of contemporary ${ }^{131} \mathrm{I}$ therapy for GD is hypothyroidism. Radioactive iodine should not be given to make patients euthyroid, as this will result in remaining partially-irradiated thyroid tissue, and it is recognized that there is an increase risk of thyroid neoplasm when children receive low doses of ${ }^{131} \mathrm{I}$ for $\mathrm{GD}[72,73]$.

When used, $>150 \mathrm{uCi}$ of ${ }^{131} \mathrm{I}$ per gm of thyroid tissue should be given to achieve thyroid ablation or hypothyroidism $[70,74]$. With large glands, higher doses of ${ }^{131}$ I (200$300 \mathrm{uCi}$ of ${ }^{131} \mathrm{I}$ per $\left.\mathrm{gm}\right)$ may be needed [74]. 
TABLE 4: UNOS data: number of recipients who received a liver transplant from 01/01/90-06/30/08 due to PTU-induced liver failure. Over the same period, there were no MMI-related transplants.

\begin{tabular}{|c|c|c|c|c|c|c|c|c|c|c|c|}
\hline \multirow{3}{*}{ Year } & \multicolumn{10}{|c|}{ Age group } & \multirow{3}{*}{$\begin{array}{l}\text { Total } \\
\qquad N\end{array}$} \\
\hline & \multicolumn{2}{|c|}{$1-5$} & \multicolumn{2}{|c|}{$11-17$} & \multicolumn{2}{|c|}{ 18-34 } & \multicolumn{2}{|c|}{$35-49$} & \multicolumn{2}{|c|}{$65+$} & \\
\hline & $N$ & $\%$ & $N$ & $\%$ & $N$ & $\%$ & $N$ & $\%$ & $N$ & $\%$ & \\
\hline 1990 & 1 & 4.3 & 0 & 0 & 0 & 0 & 1 & 4.3 & 0 & 0 & 2 \\
\hline 1991 & 0 & 0 & 0 & 0 & 1 & 4.3 & 0 & 0 & 0 & 0 & 1 \\
\hline 1992 & 0 & 0 & 0 & 0 & 1 & 4.3 & 0 & 0 & 0 & 0 & 1 \\
\hline 1993 & 0 & 0 & 1 & 4.3 & 0 & 0 & 2 & 8.7 & 0 & 0 & 3 \\
\hline 1994 & 1 & 4.3 & 1 & 4.3 & 0 & 0 & 1 & 4.3 & 0 & 0 & 3 \\
\hline 1995 & 0 & 0 & 0 & 0 & 1 & 4.3 & 0 & 0 & 0 & 0 & 1 \\
\hline 1997 & 0 & 0 & 0 & 0 & 1 & 4.3 & 0 & 0 & 1 & 4.3 & 2 \\
\hline 1998 & 0 & 0 & 0 & 0 & 1 & 4.3 & 0 & 0 & 0 & 0 & 1 \\
\hline 1999 & 0 & 0 & 1 & 4.3 & 1 & 4.3 & 0 & 0 & 0 & 0 & 2 \\
\hline 2000 & 0 & 0 & 0 & 0 & 1 & 4.3 & 0 & 0 & 0 & 0 & 1 \\
\hline 2001 & 0 & 0 & 1 & 4.3 & 0 & 0 & 1 & 4.3 & 0 & 0 & 2 \\
\hline 2004 & 0 & 0 & 0 & 0 & 2 & 8.7 & 0 & 0 & 0 & 0 & 2 \\
\hline 2006 & 0 & 0 & 0 & 0 & 1 & 4.3 & 0 & 0 & 0 & 0 & 1 \\
\hline 2007 & 0 & 0 & 1 & 4.3 & 0 & 0 & 0 & 0 & 0 & 0 & 1 \\
\hline Total & 2 & 8.7 & 5 & 21.7 & 10 & 43.5 & 5 & 21.7 & 1 & 4.3 & 23 \\
\hline
\end{tabular}

Because of theoretical concerns about whole body radiation exposure associated with ${ }^{131} \mathrm{I}$, we feel that is prudent to avoid radioactive iodine therapy in very young children, that is, less than five years of age, and to avoid doses $>10 \mathrm{mCi}$ in children less five to ten years of age if possible. These recommendations are based on theoretical concerns and not "hard data." Further studies are needed to define "how young is too young." It is recognized that there are special circumstances in which ${ }^{131} \mathrm{I}$ therapy may be required in young children, for example, a young child has developed a reaction to antithyroid medications, and proper surgical expertise is not available, or the patient is not a suitable surgical candidate.

Surgery is an acceptable form of therapy for GD in children [71]. When performed, near total or totalthyroidectomy is recommended [75]. We feel that surgery is preferred in young children when definitive therapy is required and can be performed by an experienced thyroid surgeon. In individuals with large thyroid glands ( $>80 \mathrm{gms}$ ), the response to ${ }^{131}$ I will be poor $[76,77]$, and surgery is recommended for patients with large glands.

Recent national data show that surgical complication rates are more common in children than adults, and complications in children are more than twofold higher when thyroidectomy in children is performed by pediatric or general surgeons rather than by high volume thyroid surgeons [78]. Considering the intricacies of thyroidectomy in children, it is recommended that GD surgery be performed by experienced thyroid surgeons.

\section{Limited Use of PTU}

There is no good plan for managing hepatotoxicity risk in a PTU-treated patient, other than not using the drug [7].
However, when neither prompt surgery nor ${ }^{131} \mathrm{I}$ treatments are options in a patient who has developed a toxic reaction to MMI, and antithyroid drug therapy is needed, short-term PTU use can be considered.

In this situation, parents and patients should be informed of the risk of liver failure. If patients taking PTU develop tiredness, nausea, anorexia, fever, pharyngitis, or feel ill, the medication should be immediately discontinued by the patient, a physician should be contacted, and a white blood cell count, liver function tests, and transaminase levels obtained. Alternatively, the hyperthyroid state can be controlled for several weeks prior to surgery with saturated potassium iodide solution (3 to 10 drops, p.o., tid).

Because MMI use during pregnancy is associated with an increased risk of birth defects [79-81], whereas PTU use during pregnancy is not, PTU is preferred during early pregnancy. When used during pregnancy, women should be informed of the potential risks of PTU-hepatotoxity and risks of MMI-associated fetal minor malformations when considering ATD selection during pregnancy.

\section{Conclusions}

PTU was introduced for clinical use in July 1947, and MMI was introduced in June 1950. Over the six decades that PTU has been used, reports of PTU-related liver failure and death in children and adults have accumulated in published literature and FDA databases. In comparison, we are unaware of reports of death and liver failure in children and adolescents taking MMI, and there are far fewer and less serious adverse events reported for MMI than PTU in general.

Perhaps in response to concerns that have been voiced over PTU safety over the past several years $[1,4,82]$, there has been a gratifying reduction in PTU use in the pediatric population over the past three years. Yet, it is likely that more than 1000 pediatric patients are still taking PTU in the United States. As such, it is estimated that at least one child will develop PTU-induced liver failure requiring transplantation over the next two years if PTU use continues at current levels.

Considering the above, we believe that PTU should never be used as first line treatment in children. PTU use should only be considered in rare circumstances, such as preparation for surgery in a patient allergic to MMI or in pregnancy.

Current PTU use in children taking this medication should be stopped in favor of alternate therapies to put an end to PTU-induced liver failure in children. As such, no child with GD should experience liver injury or failure, require liver transplantation, or die due to PTU, from this time forward.

\section{Acknowledgments}

Please note that the content is the responsibility of the authors alone and does not necessarily reflect the views or policies of the Department of Health and Human Services or other organizations. S. A. Rivkees thanks numerous colleagues for useful discussions on this subject. 


\section{References}

[1] S. A. Rivkees, "The treatment of Graves' disease in children," Journal of Pediatric Endocrinology and Metabolism, vol. 19, no. 9, pp. 1095-1111, 2006.

[2] R. L. Landau, "Landmark perspective: treatment of hyperthyroidism," The Journal of the American Medical Association, vol. 251, no. 13, pp. 1747-1748, 1984.

[3] E. B. Astwood, "Treatment of hyperthyroidism with thiourea and thiouracil," The Journal of the American Medical Association, vol. 251, no. 13, pp. 1743-1746, 1984.

[4] D. S. Cooper, "Antithyroid drugs," The New England Journal of Medicine, vol. 352, no. 9, pp. 905-917, 2005.

[5] D. L. Geffner, M. Azukizawa, and J. M. Hershman, "Propylthiouracil blocks extrathyroidal conversion of thyroxine to triiodothyronine and augments thyrotropin secretion in man," The Journal of Clinical Investigation, vol. 55, no. 2, pp. 224-229, 1975.

[6] S. A. Rivkees and D. R. Mattison, "Ending propylthiouracil (PTU)-induced liver failure in children," The New England Journal of Medicine, vol. 360, no. 15, pp. 1574-1575, 2009.

[7] Eunice Kennedy Shriver National Institute of Child Health and Human Development, "Conference Proceeding: Hepatic Toxicity Following Treatment for Pediatric Graves' Disease Meeting," October 2008, http://bpca.nichd.nih.gov/outreach/ index.cfm.

[8] F. D. Moore, "Toxic manifestations of thiouracil therapy," The Journal of the American Medical Association, vol. 130, pp. 315319, 1946.

[9] A. R. Colwell Jr., D. E. Sando, and S. J. Lang, "Propylthiouracilinduced agranulocytosis, toxic hepatitis, and death," The Journal of the American Medical Association, vol. 148, no. 8, pp. 639-641, 1952.

[10] M. J. Eisen, "Fulminant hepatitis during treatment with propylthiouracil," The New England Journal of Medicine, vol. 249, no. 20, pp. 814-816, 1953.

[11] M. S. Fedotin and L. G. Lefer, "Liver disease caused by propylthiouracil," Archives of Internal Medicine, vol. 135, no. 2, pp. 319-321, 1975.

[12] L. N. Parker, "Letter: hepatitis and propylthiouracil," Annals of Internal Medicine, vol. 82, no. 2, pp. 228-229, 1975.

[13] A. A. Mihas, P. Holley, R. S. Koff, and B. I. Hirschowitz, "Fulminant hepatitis and lymphocyte sensitization due to propylthiouracil," Gastroenterology, vol. 70, no. 5, part 1, pp. 770-774, 1976.

[14] C. M. Reddy, "Propylthiouracil and hepatitis: a case report," Journal of the National Medical Association, vol. 71, no. 12, pp. 1185-1186, 1979.

[15] M. Weiss, D. Hassin, and H. Bank, "Propylthiouracil-induced hepatic damage," Archives of Internal Medicine, vol. 140, no. 9, pp. 1184-1185, 1980.

[16] F. Pacini, V. Sridama, and S. Refetoff, "Multiple complications of propylthiouracil treatment: granulocytopenia, eosinophilia, skin reaction and hepatitis with lymphocyte sensitization," Journal of Endocrinological Investigation, vol. 5, no. 6, pp. 403407, 1982.

[17] W. A. Parker, "Prophylthiouracil-induced hepatotoxicity," Clinical Pharmacy, vol. 1, no. 5, pp. 471-474, 1982.

[18] M. M. Safani, D. S. Tatro, and P. Rudd, "Fatal propylthiouracilinduced hepatitis," Archives of Internal Medicine, vol. 142, no. 4, pp. 838-839, 1982.

[19] M. S. Fedotin, "Correction. Propylthiouracil and hepatitis," Archives of Internal Medicine, vol. 144, no. 10, pp. 2100-2101, 1984.
[20] J. S. Hanson, "Propylthiouracil and hepatitis. Two cases and a review of the literature," Archives of Internal Medicine, vol. 144, no. 5, pp. 994-996, 1984.

[21] C. A. Bloch, L. J. Jenski, W. F. Balistreri, and L. M. Dolan, "Propylthiouracil-associated hepatitis," Archives of Internal Medicine, vol. 145, no. 11, pp. 2129-2130, 1985.

[22] B. Z. Garty, R. Kauli, J. Ben-Ari, E. Lubin, M. Nitzan, and Z. Laron, "Hepatitis associated with propylthiouracil treatment," Drug Intelligence and Clinical Pharmacy, vol. 19, no. 10, pp. 740-742, 1985.

[23] D. S. Seidman, E. Livni, B. Ilie, and I. Blum, "Propylthiouracilinduced cholestatic jaundice," Journal of Toxicology: Clinical Toxicology, vol. 24, no. 4, pp. 353-360, 1986.

[24] A. Limaye and P. R. Ruffolo, "Propylthiouracil-induced fatal hepatic necrosis," American Journal of Gastroenterology, vol. 82, no. 2, pp. 152-154, 1987.

[25] M. M. Jonas and M. S. Eidson, "Propylthiouracil hepatotoxicity: two pediatric cases and review of the literature," Journal of Pediatric Gastroenterology and Nutrition, vol. 7, no. 5, pp. 776-779, 1988.

[26] B. Baker, B. Shapiro, L. M. Fig, D. Woodbury, J. C. Sisson, and W. H. Beierwaltes, "Unusual complications of antithyroid drug therapy: four case reports and review of literature," Thyroidology, vol. 1, no. 1, pp. 17-26, 1989.

[27] G. Maggiore, D. Larizza, R. Lorini, C. De Giacomo, M. S. Scotta, and F. Severi, "Propylthiouracil hepatotoxicity mimicking autoimmune chronic active hepatitis in a girl," Journal of Pediatric Gastroenterology and Nutrition, vol. 8, no. 4, pp. 547-548, 1989.

[28] C. V. Morris, R. M. Goldstein, J. B. Cofer, H. Solomon, and G. B. Klintmalm, "An unusual presentation of fulminant hepatic failure secondary to propylthiouracil therapy," Clinical transplants, p. 311, 1989.

[29] J. L. Kirkland, "Propylthiouracil-induced hepatic failure and encephalopathy in a child," DICP: The Annals of Pharmacotherapy, vol. 24, no. 5, pp. 470-471, 1990.

[30] S. A. Peter, "Propylthiouracil-associated hepatitis," Journal of the National Medical Association, vol. 83, no. 1, pp. 75-77, 1991.

[31] M. Levy, "Propylthiouracil hepatotoxicity: a review and case presentation," Clinical Pediatrics, vol. 32, no. 1, pp. 25-29, 1993.

[32] S. A. Westphal, "Hepatotoxicity from propylthiouracil," Southern Medical Journal, vol. 87, no. 9, pp. 943-947, 1994.

[33] J. T. Hardee, A. L. Barnett, A. Thannoun, B. Echtesad, D. Wheeler, and M. M. Jamal, "Propylthiouracil-induced hepatotoxicity," Western Journal of Medicine, vol. 165, no. 3, pp. 144-147, 1996.

[34] J. K. Ruiz, G. V. Rossi, H. A. Vallejos, R. W. Brenet, I. B. Lopez, and A. A. Escribano, "Fulminant hepatic failure associated with propylthiouracil," Annals of Pharmacotherapy, vol. 37, no. 2, pp. 224-228, 2003.

[35] G. Testa, J. Trevino, D. Bogetti, et al., "Liver transplantation for propylthiouracil-induced acute hepatic failure," Digestive Diseases and Sciences, vol. 48, no. 1, pp. 190-191, 2003.

[36] S. Aydemir, Y. Ustundag, T. Bayraktaroglu, I. O. Tekin, I. Peksoy, and A. U. Unal, "Fulminant hepatic failure associated with propylthiouracil: a case report with treatment emphasis on the use of plasmapheresis," Journal of Clinical Apheresis, vol. 20, no. 4, pp. 235-238, 2005.

[37] W. E. B. Sipe, M. Su, A. Posselt, G. E. Kim, J. A. Quiros, and P. Rosenthal, "Propylthiouracil-associated liver failure presenting as probable autoimmune hepatitis in a child with 
Graves' disease," Pediatric Transplantation, vol. 10, no. 4, pp. 525-528, 2006.

[38] W. Khovidhunkit and R. V. Farese Jr., "Resolution of propylthiouracil-induced hepatic failure after treatment of thyrotoxicosis," Western Journal of Medicine, vol. 167, no. 5, pp. 353-356, 1997.

[39] D. R. Lock and Z. M. Sthoeger, "Severe hepatotoxicity on beginning propylthiouracil therapy," Journal of Clinical Gastroenterology, vol. 24, no. 4, pp. 267-269, 1997.

[40] M. Waseem, K. G. Seshadri, and U. M. Kabadi, "Successful outcome with methimazole and lithium combination therapy for propylthiouracil-induced hepatotoxicity," Endocrine Practice, vol. 4, no. 4, pp. 197-200, 1998.

[41] R. Deidiker and D. E. deMello, "Propylthiouracil-induced fulminant hepatitis: case report and review of the literature," Pediatric Pathology and Laboratory Medicine, vol. 16, no. 5, pp. 845-852, 1996.

[42] S. Özenírler, C. Tuncer, Ü. Boztepe, et al., "Propylthiouracilinduced hepatic damage," Annals of Pharmacotherapy, vol. 30, no. 9, pp. 960-963, 1996.

[43] K. V. Williams, S. Nayak, D. Becker, J. Reyes, and L. A. Burmeister, "Fifty years of experience with propylthiouracilassociated hepatotoxicity: what have we learned?" The Journal of Clinical Endocrinology \& Metabolism, vol. 82, no. 6, pp. 1727-1733, 1997.

[44] D. M. Arab, D. A. Malatjalian, and R. S. Rittmaster, "Severe cholestatic jaundice in uncomplicated hyperthyroidism treated with methimazole," The Journal of Clinical Endocrinology \& Metabolism, vol. 80, no. 4, pp. 1083-1085, 1995.

[45] C. Lersch, M. Seige, W. Natrath, et al., "Cholestasis induced by hyperthyroidism after liver transplantation," Digestion, vol. 56, no. 5, pp. 429-432, 1995.

[46] G. P. Schwab, G. J. Wetschcr, W. Vogl, and E. Redmond, "Methimazole-induced cholestatic liver injury, mimicking sclerosing cholangitis," Langenbecks Archiv fur Chirurgie, vol. 381, no. 4, pp. 225-227, 1996.

[47] Y. T. Hung, W. K. Yu, and E. Chow, "Delayed cholestatic hepatitis due to methimazole," Hong Kong Medical Journal, vol. 5, no. 2, pp. 200-201, 1999.

[48] N. E. Mikhail, "Methimazole-induced cholestatic jaundice," Southern Medical Journal, vol. 97, no. 2, pp. 178-182, 2004.

[49] L. S. Ramos-Bonner, T. H. Goldberg, S. Moyer, and C. Anastasopoulou, "Methimazole-induced cholestatic jaundice in an elderly hyperthyroid patient," American Journal Geriatric Pharmacotherapy, vol. 5, no. 3, pp. 236-240, 2007.

[50] R. Gemma, Y. Suzuki, I. Tanaka, T. Taminato, T. Yoshimi, and T. Kanno, "Lactate dehydrogenase (LDH)-linked immunoglobulin in a patient with Graves' disease treated with methimazole," Internal Medicine, vol. 31, no. 3, pp. 377-379, 1992.

[51] K. A. Woeber, "Methimazole-induced hepatotoxicity," Endocrine Practice, vol. 8, no. 3, pp. 222-224, 2002.

[52] G. Schmidt, G. Borsch, K.-M. Muller, and M. Wegener, "Methimazole-associated cholestatic liver injury: case report and brief literature review," Hepato-Gastroenterology, vol. 33, no. 6, pp. 244-246, 1986.

[53] A. Mamianetti, A. Munoz, R. D. Ronchetti, et al., "Acquired sideroblastic anemia and cholestasis in a hyperthyroid patient treated with methimazole and atenolol," Medicina, vol. 55, no. 6, pp. 693-696, 1995.

[54] H. Kang, J. D. Choi, I. G. Jung, et al., "A case of methimazoleinduced acute hepatic failure in a patient with chronic hepatitis B carrier," Korean Journal of Internal Medicine, vol. 5, no. 1, pp. 69-73, 1990.

[55] S. A. Rivkees, C. Sklar, and M. Freemark, "The management of Graves' disease in children, with special emphasis on radioiodine treatment," The Journal of Clinical Endocrinology \& Metabolism, vol. 83, no. 11, pp. 3767-3776, 1998.

[56] N. S. Glaser and D. M. Styne, "Predicting the likelihood of remission in children with Graves' disease: a prospective, multicenter study," Pediatrics, vol. 121, no. 3, pp. e481-e488, 2008.

[57] J. I. Hamburger, "Management of hyperthyroidism in children and adolescents," The Journal of Clinical Endocrinology \& Metabolism, vol. 60, no. 5, pp. 1019-1024, 1985.

[58] F. Kaguelidou, C. Alberti, M. Castanet, M.-A. Guitteny, P. Czernichow, and J. Léger, "Predictors of autoimmune hyperthyroidism relapse in children after discontinuation of antithyroid drug treatment," The Journal of Clinical Endocrinology \& Metabolism, vol. 93, no. 10, pp. 3817-3826, 2008.

[59] B. M. Lippe, E. M. Landaw, and S. A. Kaplan, "Hyperthyroidism in children treated with long term medical therapy: twenty-five percent remission every two years," The Journal of Clinical Endocrinology \& Metabolism, vol. 64, no. 6, pp. 12411245, 1987.

[60] C. Ma, A. Kuang, J. Xie, and G. Liu, "Radioiodine treatment for pediatric Graves' disease," Cochrane Database of Systematic Reviews, no. 3, Article ID CD006294, 2008.

[61] P. H. Somnuke, P. Pusuwan, S. Likitmaskul, J. Santiprabhob, and P. Sawathiparnich, "Treatment outcome of Graves' disease in Thai children," Journal of the Medical Association of Thailand, vol. 90, no. 9, pp. 1815-1820, 2007.

[62] L. Ward, C. Huot, R. Lambert, C. Deal, R. Collu, and G. Van Vliet, "Outcome of pediatric Graves' disease after treatment with antithyroid medication and radioiodine," Clinical and Investigative Medicine, vol. 22, no. 4, pp. 132-139, 1999.

[63] L. Lazar, O. Kalter-Leibovici, A. Pertzelan, N. Weintrob, Z. Josefsberg, and M. Phillip, "Thyrotoxicosis in prepubertal children compared with pubertal and postpubertal patients," The Journal of Clinical Endocrinology \& Metabolism, vol. 85, no. 10, pp. 3678-3682, 2000.

[64] M. W. Russo, J. A. Galanko, R. Shrestha, M. W. Fried, and P. Watkins, "Liver transplantation for acute liver failure from drug induced liver injury in the United States," Liver Transplantation, vol. 10, no. 8, pp. 1018-1023, 2004.

[65] S. A. Rivkees and D. R. Mattison, "Propylthiouracil (PTU)induced liver failure and recommendations for the discontinuation of PTU use in children," International Journal of Pediatric Endocrinology. In press.

[66] L. Wartofsky, D. Glinoer, B. Solomon, et al., "Differences and similarities in the diagnosis and treatment of Graves' disease in Europe, Japan, and the United States." Thyroid, vol. 1, no. 2, pp. 129-135, 1991.

[67] W. C. Nicholas, R. G. Fischer, R. A. Stevenson, and J. D. Bass, "Single daily dose of methimazole compared to every 8 hours propylthiouracil in the treatment of hyperthyroidism," Southern Medical Journal, vol. 88, no. 9, pp. 973-976, 1995.

[68] J. Tajiri and S. Noguchi, "Antithyroid drug-induced agranulocytosis: how has granulocyte colony-stimulating factor changed therapy?" Thyroid, vol. 15, no. 3, pp. 292-297, 2005.

[69] D. S. Cooper, D. Goldminz, A. A. Levin, et al., "Agranulocytosis associated with antithyroid drugs. Effects of patient age and drug dose," Annals of Internal Medicine, vol. 98, no. 1, pp. 26-29, 1983. 
[70] S. A. Rivkees and C. Dinauer, "Controversy in clinical endocrinology: an optimal treatment for pediatric Graves' disease is radioiodine," The Journal of Clinical Endocrinology \& Metabolism, vol. 92, no. 3, pp. 797-800, 2007.

[71] J. A. Lee, M. M. Grumbach, and O. H. Clark, "Controversy in clinical endocrinology: the optimal treatment for pediatric Graves' disease is surgery," The Journal of Clinical Endocrinology \& Metabolism, vol. 92, no. 3, pp. 801-803, 2007.

[72] G. E. Sheline, K. R. McCormack, and M. Galante, "Thyroid nodules occurring late after treatment of thryotoxicosis with radioiodine," The Journal of Clinical Endocrinology \& Metabolism, vol. 22, pp. 8-17, 1962.

[73] B. M. Dobyns, G. E. Sheline, J. B. Workman, E. A. Tompkins, W. M. McConahey, and D. V. Becker, "Malignant and benign neoplasms of the thyroid in patients treated for hyperthyroidism: a report of the cooperative thyrotoxicosis therapy. Follow up study," The Journal of Clinical Endocrinology \& Metabolism, vol. 38, no. 6, pp. 976-998, 1974.

[74] S. A. Rivkees and E. A. Cornelius, "Influence of iodine131 dose on the outcome of hyperthyroidism in children," Pediatrics, vol. 111, no. 4, pp. 745-749, 2003.

[75] P. Miccoli, P. Vitti, T. Rago, et al., "Surgical treatment of Graves' disease: subtotal or total thyroidectomy?" Surgery, vol. 120, no. 6, pp. 1020-1025, 1996.

[76] H. Peters, C. Fischer, U. Bogner, C. Reiners, and H. Schleusener, "Reduction in thyroid volume after radioiodine therapy of Graves' hyperthyroidism: results of a prospective, randomized, multicentre study," European Journal of Clinical Investigation, vol. 26, no. 1, pp. 59-63, 1996.

[77] H. Peters, C. Fischer, U. Bogner, C. Reimers, and H. Schleusener, "Treatment of Graves' hyperthyroidism with radioiodine: results of a prospective randomized study," Thyroid, vol. 7, no. 2, pp. 247-251, 1997.

[78] J. A. Sosa, C. T. Tuggle, T. S. Wang, et al., "Clinical and economic outcomes of thyroid and parathyroid surgery in children," The Journal of Clinical Endocrinology \& Metabolism, vol. 93, no. 8, pp. 3058-3065, 2008.

[79] P. Barbero, C. Ricagni, G. Mercado, R. Bronberg, and M. Torrado, "Choanal atresia associated with prenatal methimazole exposure: three new patients," American Journal of Medical Genetics, vol. 129A, no. 1, pp. 83-86, 2004.

[80] P. Barbero, R. Valdez, H. Rodríguez, et al., "Choanal atresia associated with maternal hyperthyroidism treated with methimazole: a case-control study," American Journal of Medical Genetics Part A, vol. 146A, no. 18, pp. 2390-2395, 2008.

[81] R. M. Valdez, P. M. Barbero, R. C. Liascovich, L. F. De Rosa, M. A. Aguirre, and L. G. Alba, "Methimazole embryopathy: a contribution to defining the phenotype," Reproductive Toxicology, vol. 23, no. 2, pp. 253-255, 2007.

[82] S. A. Rivkees, "Graves' disease therapy in children: truth and inevitable consequences," Journal of Pediatric Endocrinology \& Metabolism, vol. 20, no. 9, pp. 953-955, 2007. 